\title{
The Influence of BYOD on Results of Students' Learning
}

\section{La influencia de BYOD en los resultados del aprendizaje de los estudiantes}

\author{
Maya Livson \\ Moscow Polytechnic University, Moscow, Russia \\ https://orcid.org/0000-0003-0713-0417 \\ Kapitolina Leonidovna Ulanova \\ Peoples' Friendship University of Russia (RUDN University), Moscow, Russia \\ https://orcid.org/0000-0002-0190-930X \\ Vladimir Vladimirovich Pertsev \\ Bunin Yelets State University, Yelets, Russia \\ https://orcid.org/0000-0002-1724-7320 \\ Sergey Vasilyevich Dudynov \\ Mordovian State University, Saransk, Russia \\ https://orcid.org/0000-0002-0934-549X \\ Aleksey Valeryevich Novikov \\ Research Institute of the Federal Penitentiary Service of Russia, Moscow, Russia \\ Astrakhan State University, Astrakhan, Russia \\ Russian Customs Academy, Lyubercy, Moscow Region, Russia \\ https://orcid.org/0000-0002-6418-7543
}

*Correspondencia

Email: maya_livson@mail.ru 


\section{Summary}

This work analyzes the influence and efficiency of BYOD for learning students and academic perfection. The relevance of mobile technologies for learning has been substantiated. The influence of BYOD on academic performance of undergraduate students in terms of their test scores and final course marks, as well as on quality of work on selected course projects and on level of satisfaction with the BYOD course, has been experimentally studied. It has been proved that BYOD exerts positive influence on learning and academic achievements of students measured by their academic test scores, by their final marks and quality of their classroom work, as well as that the implementation of BYOD will stimulate and motivate students, thus affecting their level of involvement and creation of independent learning. The experimental results should be used as a guide for persons making decisions as well as for practical specialists in the field of education, especially in the area of BYOD and mobile learning, which will save significant expenses for stationary learning (for instance, concerning desktop computers, projectors, etc.). Scientific novelty of the studies is that the influence of BYOD on academic performance of students in terms of their test scores and final course marks, as well as on quality of students' work on selected course projects and on level of satisfaction with the BYOD course, has been comprehensively analyzed.

Keywords: Bring Your Own Device (BYOD), Mobile Learning (M-Learning), ICT Integration, Academic Achievements, Students' Learning, Students' Attitude.

\section{Resumen}

Este trabajo analiza la influencia y la eficiencia de BYOD para el aprendizaje de los estudiantes y la perfección académica. Se ha comprobado la relevancia de las tecnologías móviles para el aprendizaje. Se ha estudiado experimentalmente la influencia de BYOD en el rendimiento académico de los estudiantes de pregrado en términos de los puntajes de sus exámenes y calificaciones finales del curso, así como en la calidad del trabajo en proyectos de cursos seleccionados y en el nivel de satisfacción con el curso BYOD. Se ha comprobado que BYOD ejerce una influencia positiva en el aprendizaje y los logros académicos de los estudiantes medidos por sus puntajes en las pruebas académicas, por sus calificaciones finales y la calidad de su trabajo en el aula, así como que la implementación de BYOD estimulará y motivará a los estudiantes, afectando así su nivel de implicación y creación de aprendizaje independiente. Los resultados experimentales deben usarse como una guía para las personas que toman decisiones, así como para los especialistas prácticos en el campo de la educación, especialmente en el área de BYOD y aprendizaje móvil, lo que ahorrará gastos significativos para el aprendizaje estacionario (por ejemplo, en relación con las computadoras de escritorio)., proyectores, etc.). La novedad científica de los estudios es que la influencia de BYOD en el rendimiento académico de los estudiantes en términos de los puntajes de sus exámenes y calificaciones finales del curso, así como en la calidad del trabajo de los estudiantes en proyectos de cursos seleccionados y en el nivel de satisfacción con el curso BYOD, ha sido analizado de forma exhaustiva.

Palabras clave: Traiga su propio dispositivo (BYOD), Aprendizaje móvil (MLearning), Integración de las TIC, Logros académicos, Aprendizaje de los estudiantes, Actitud de los estudiantes. 


\section{Introduction}

Modern trends in education highlight the tools and services of ICT as well as the role, which they play in achievement of education targets and improvement of learning experience and results of students (Tereshchenko et al., 2020; Varenina et al., 2020). Under the conditions of popularization of mobile devices, improvement of their efficiency and available scope of mobile applications, the learning process is supplemented by learning aids both for classroom work and for organization of distance learning (Ramazanova et al., 2020; Akhyadov, Goncharov, Makushkin, 2020). The main focus of the involvement of mobile devices in the learning process is in their ultra-portability together with other technical aids, as well as in comprehensive provision of overall audience (at present, almost everyone has a smartphone of basic level) and opportunity to interact actively in distance mode (Goncharov et al., 2020; Alekseev et al., 2020).

The researchers (Franklin, Peng, 2008; Hooft, Vahey, 2007; Liu, 2007; Myers, Beigl, 2003) mention that mobile learning is suitable and dynamic use of technology, which is easily available for most teachers and students. Universal Design for Learning (UDL) also stands for for innovative design and delivery of recommendations, such as mobile technologies for students with various demands in learning (King-Sears, 2009).

Mobile learning provides flexibility and mechanism, allowing student to freely obtain education in most learning environments (Afreen, 2014; Hloden, 2010). Many educational systems use mobile technologies as a way to connect students to ambient world (Ash, 2009; Hwang, Tsai, 2011). Mobile learning devices are comparatively inexpensive and available, they often enhance complicated concepts of learning and mechanism of cooperation beyond classroom learning (Vázquez-Cano, 2014). The technology of mobile learning adjusts students due to moderate price, availability in most households, including those without notebooks or desktop computers and Internet connection (Foti, Mendez, 2014; El-Hussein, Cronje, 2010).

One of the dominating trends of modern mobile learning is related with integration of Bring Your Own Device (BYOD) concept, which firstly appeared in corporate culture but then was reinterpreted and adopted for application in learning (Ally, 2013).

At first the BYOD referred to the use of own mobile devices by company employees (smartphones, tablets, notebooks). The employees have access to databases and company software aiming at optimization of work issues (Gil-Rodríguez, Rebaque-Rivas, 2010). In learning process, the BYOD refers to the use of a mobile device as additional data source in the course of execution of various tasks, both classroom and independent. The simplest and the most common method to use own mobile device is in reproducing the electronic version of teaching aid, which is in free access for distance course (Graham, 2016).

The BYOD technology, when students bring their mobile devices and use them during classes, has proved to be successful in education and at present is one of the most relevant ICTs in learning process (Johnson, 2012). In the environment of digital transformation of society, the mobility of teaching staff increases, teachers become less connected to working place due to using personal mobile devices (notebooks, tablets, phones) to solve current issues in the frames of the BYOD concept, in single information field. This greatly increases efficiency and productivity (Kinash, Brand, Mathew, 2012).

Conventional education in classrooms, where teacher was the main figure, develops due to the system of active learning comprised of the BYOD technology and platforms for interactive communication with sensor displays, where each student can play active role in learning process (Kobus, Rietveld, van Ommeren, 2013). This creates favorable conditions for interaction between students and teacher, encourages students to participate more willingly in learning processes (LaMaster, Stager, 2012). 
This work has hypothesized that BYOD influences positively learning and academic performance of students measured by their academic test scores, their final marks, and quality of their classroom work. In addition, the work has hypothesized that implementation of BYOD will stimulate and motivate students, thus influencing their level of involvement in creation of independent learning.

On the basis of the experimental results, it can be concluded that the initially formulated objective has been achieved.

\section{Literature review}

Numerous studies (Selwyn, 2007; Woods, Baker, Hopper, 2004; Sherblom, 2010; Hrastinski, 2008; Bernard et al., 2014) devoted to the influence of ICT in total and initiatives/software of e-learning on the academic performances of students confirm close interconnection between the success in learning and the use of ICT. Both common students and those with peculiar demands at all levels demonstrate the following: 1. significant improvement of academic performance for all disciplines and levels of marks (for instance, cumulative average test scores, individual course marks and standardized test results on the basis of norms); 2. easier work as well as its efficiency and quality; 3. closer cooperation and formation of communicative skills and skills of research activity; 4. higher interest, attentiveness and involvement into independent learning and personal growth; 5. improved availability of course content and learning aids; 6 . even more satisfaction with learning.

The use of ICT also affects teachers, expanding their practice (for instance, teaching strategy, execution of learning programs and management of classes) (Falloon, 2015; Safar, 2017).

The works considered in this section analyze the influence of BYOD supported elearning environment on learning experience of students, academic achievements (performance), improvement, attitude, motivation, involvement and satisfaction as well as the influence of BYOD on teaching practice.

BYOD is an ICT mediated model of mobile learning (m-learning), which encourages students to bring their own devices with various applications and embedded functions to school in order to use them in learning (and teaching) aims (Cochrane et al., 2014; O'Bannon, Thomas, 2015).

The use of BYOD exerts positive effect in educational context (Livas, Katsanakis, Vayia, 2019), allowing to individualize and to arrange flexibly the education process (Cheng, Guan, Chau, 2016). The fact that students may use their own devices maintains positive attitude both of students (Song, 2014) and of teachers to the considered model (Parsons, Adhikar, 2016).

Similarly, due to opportunity of connection of digital devices, the cooperation among students is encouraged as well as collective knowledge construction. Therefore, the use of BYOD program optimizes academic performance of students (Hung, 2017), resulting in improvement of their marks and promoting joint and independent learning (Hao, 2016). Moreover, this combination allows students to perform efficiently activities in any context, since they are familiar with configuration of their personal devices (Nuhoglu, Gundiz, Akkoyunlu, 2019). Working with mobile devices promotes personally-oriented learning of students, provides numerous opportunities for differentiated, autonomous and individual learning, encourages implementation of innovative forms of teaching, and expansion of conventional forms of learning (Henderson, Gibson, Gibb, 2013). 
BYOD allows individuals to get access to computer network of establishment using their own ICT device to perform their working tasks. As a rule, students prefer to use their own mobile devices for academic activities (Zahadat et al., 2015).

The use of BYOD program simplifies storage and recovery of files; however, the portability of devices causes negative limitations related with weight and dimensions (Song, Wen, 2018). In addition, the use of this model allows students to understand better the concepts and supports mutual discussions in order to construct learning; however, its proper development should be based on adequate teacher training (Welsh et al., 2018). Positive consequences are observed also in students' learning, which could influence students' behavior, though, many students could refuse to use it because of possible loss or damage of the device (Stonebraker et al., 2014).

At least the same important significance of BYOD is economy of expenses, which, according to (Alden, 2013), makes it possible for universities to spend money for IT assets and infrastructure, encouraging students and teachers to follow the BYOD principle, since each device (phone, tablet, notebook) can be connected to network in order to access to corporate data and systems using cloud technologies. Therefore, everybody can readily obtain access to university network and required learning material.

The experts (Khedr, Idrees, 2017; Tomasz, Bajdor, 2015) believe that the wide-scale implementation of mobile devices in recent years is a trend, which is developed in parallel with cloud computations. In the course of transition to BYOD in business, educational establishments also try to benefit from improved mobility. R.G. Lennon believes (2012) that BYOD is characterized by the following advantages: students' involvement; availability of resources; simplifying of teaching and learning.

The research performed in Hong Kong university (Kong, Song, 2015) was devoted to the influence of program of personalized learning center with participation of BYOD on reflexive involvement of students. The model with three aspects - intellectual, personal, and social reflexive involvement - was used. Participants in the research were proposed to take with them and to use their own portable ICT devices as a personalized learning center in order to maintain and strengthen their reflexive activity. Quantitative and qualitative data of inquiries and interviews demonstrated that the use of BYOD exerted significant positive influence on achievement of reflexive involvement by students in all three aspects and on content of elearning. The students also recognized the value of BYOD and that the group cooperation with peers and experts could expand their knowledge. Such kind of reflexive involvement, encouraged by BYOD, should promote deep learning and personal growth.

While considering another aspect of BYOD, the research (Parsons, Adhikari, 2016) was devoted to thorough analysis of perception of the initiative by students and teachers. The obtained results highlighted the obstacles during transition to BYOD, as well as hidden educational advantages of BYOD for teaching, learning, and training students for digital era based on knowledge. Most participants in the research reported about positive changes in learning and class management; However, some teachers also expressed concern about radical changes in BYOD.

Similar research (Burns, Lohenry, 2010) was devoted to the influence of iPad (using a BYOD program) on ability of students to work together. 100 students participated in this research, who every day used iPad to perform most of their academic tasks. The data were acquired during three years using inquiries, observations of researchers from informal talks with teachers and students, conversations among students and reflection: captured video/audio data. The results demonstrated that the use of BYOD iPads exerted significant positive influence on ability of students to work together and in combination with cloud ICT devices/applications and services, such as Google Docs, allowed to expand this cooperation and communication on a 
wider audience beyond classroom and to combine formal and informal environment of teaching and learning.

The research (Dunleavy, Heinecke, 2008) performed with the group of students of secondary school analyzed the influence of BYOD on academic performance in the following disciplines: mathematics and natural sciences. The program was aimed at improvement of efficiency of educational process to achieve higher success measured by traditional indices, such as scores of state standard tests, school abilities test/ scholastic assessment test (SAT), test scores, estimation and preparation for future working skills. The analysis revealed significant positive influence of BYOD, as well as gender related advantage (BYOD male students demonstrated better performances than females).

In addition, M. Hawkes, C. Hategekimana (2009) analyzed the influence of ICT on academic performance of American students in university covering wide integration of ICT in all disciplines. The research was performed with quasi-experimental design comparing classroom marks of reference (nonmobile computing) and experimental (mobile computing) student groups. The selected courses were comprised of students of various specialties. In order to provide data quality, the final analysis was comprised of the marks received for tests performed in classrooms under the guidance of teacher. The results demonstrated that positive differences in the marks were detected in the courses supported by ICT.

Another research by Y. Song, S.C. Kong (2017) was concentrated on detection and demonstration of opportunities and limitations of BYOD for teaching and learning in universities from the teachers' point of view. The analysis revealed seven opportunities of BYOD for various applications in teaching and learning: (1) tool to access resources; (2) tool to collect resources; (3) tool to provide resources; (4) tool of joint use of resources; (5) tool of communication; (6) tool of knowledge construction; and (7) tool of presentation and augmented reality. The results also demonstrated three limitations of BYOD accepted by teachers in pedagogical practice: (1) technical limitations (for instance, functionality of application, limited screen size, Wi-Fi infrastructure, unavailability of charging and relative computing power of desktop computer in comparison with m-device); (2) social limitations (for instance, justice, support of learning and absence of personal communications); and (3) personal limitations (for instance, technical competence of teaching staff, technical competence of students, unwillingness to use BYOD, time consumption, selection of application and pedagogics corresponding to BYOD).

\section{Methods}

On the basis of the objective of this research and the presented literature review, the following tasks were formulated:

1. To determine the influence of BYOD on academic performance of undergraduate students in terms of their test scores and final course marks.

2. To determine the influence of BYOD on quality of work on selected course projects.

3. To determine the level of satisfaction with the BYOD course.

The experimental study was used for comparison of current and final marks, as well as for estimation of attitude, motivation, involvement and perception of BYOD for two groups of students: experimental (BYOD) and reference (non-BYOD). The students were taught the same course by the same teacher (researcher). The experimental group brought to school their own mobile ICT devices (notebooks, tablets, and smartphones), whereas the reference group used desktop computers provided by educational entity. This research model was aimed at 
opportunity to better study the data reflecting the students' experience and to reveal the influence of BYOD on learning and academic performance of students.

A sample of 100 senior students participated in this research. The students were subdivided into two equal groups (reference and experimental), 50 students in each group. The sample was comprised of students of various specialization.

The data were acquired during one semester in various forms: test results, marks for projects/assignments, final marks, attendance records, classroom observations, students' artifacts, evaluations of skills of students' communication and cooperation, and interview. The participants were notified that their data would be kept confidential and would only be used for statistical analysis.

A set of mathematical methods was used for analysis of the acquired data. These methods corresponded to the main parametric assumptions required for their implementation. Descriptive analysis was applied: calculation of frequency, percentage, average value and standard deviation. A series of comparisons - t-test for independent samples - was also used to evaluate differences between two groups of students in terms of academic performance (i.e., their test scores and marks for specific object-oriented projects performed in classroom under the teacher's guidance), as well as attitude, motivation, involvement and perception.

Three various criteria were used to evaluate the learning results: (1) students' test scores and their final course marks; (2) quality of work on specified projects; and (3) level of satisfaction with the course (attitude, motivation, involvement and interest) together with their attendance and participation. Each criterion was analyzed and presented separately.

\section{Results}

The influence of BYOD on academic performance of students is summarized in Tables $1-2$.

Table (1): Frequency and percentage of academic performance of students in Test 1, Test 2, and final marks

\begin{tabular}{|c|c|c|c|c|c|c|c|c|c|c|c|c|}
\hline & \multicolumn{12}{|c|}{ Group } \\
\hline & \multicolumn{6}{|c|}{ Reference } & \multicolumn{6}{|c|}{ Experimental } \\
\hline & \multicolumn{2}{|c|}{$\begin{array}{l}\text { below } \\
\text { medium }\end{array}$} & \multicolumn{2}{|c|}{ medium } & \multicolumn{2}{|c|}{$\begin{array}{l}\text { above } \\
\text { medium }\end{array}$} & \multicolumn{2}{|c|}{$\begin{array}{l}\text { below } \\
\text { medium }\end{array}$} & \multicolumn{2}{|c|}{ medium } & \multicolumn{2}{|c|}{\begin{tabular}{|l|} 
above \\
medium
\end{tabular}} \\
\hline Category & $\mathrm{N}$ & $\%$ & $\mathrm{~N}$ & $\%$ & $\mathrm{~N}$ & $\%$ & $\mathrm{~N}$ & $\%$ & $\mathrm{~N}$ & $\%$ & $\mathrm{~N}$ & $\%$ \\
\hline Test 1 (scores) & 16 & 32 & 19 & 38 & 15 & 30 & 0 & 0 & 14 & 28 & 36 & 72 \\
\hline Test 2 (scores) & 20 & 40 & 15 & 30 & 15 & 30 & 0 & 0 & 12 & 24 & 38 & 76 \\
\hline $\begin{array}{ll}\text { Final } & \text { cours } \\
\text { marks } & \end{array}$ & $\mathrm{e} 28$ & 56 & 13 & 26 & 9 & 18 & 3 & 6 & 19 & 38 & 28 & 56 \\
\hline
\end{tabular}

Table (2): Average and standard deviations of academic performance of students in Test 1, Test 2, and final marks

\begin{tabular}{|l|l|l|l|l|l|}
\hline Category & Group & $\mathrm{N}$ & $\mathrm{M}$ & $\mathrm{SD}$ & t-test \\
\hline \multirow{2}{*}{ Test 1 (scores) } & 1. Reference & 50 & 18.84 & 4.116 & -3.843 \\
\cline { 2 - 5 } & 2. Experimental & 50 & 22.44 & 1.816 & \\
\hline \multirow{2}{*}{ Test 2 (scores) } & 1. Reference & 50 & 18.56 & 4.673 & \multirow{2}{*}{-4.121} \\
\cline { 2 - 5 } Final course marks & 2. Experimental & 50 & 22.84 & 1.784 & \\
\cline { 2 - 5 } & 1. Reference & 50 & 71.84 & 15.668 & \multirow{2}{*}{-4.810} \\
\cline { 2 - 5 } & 2. Experimental & 50 & 88.96 & 6.769 & \\
\hline
\end{tabular}


The influence of BYOD on quality of work of students on selected course projects is summarized in Tables 3-4.

Table (3): Frequency and percentage of work quality on Project 1, Project 2, Project 3, and Project 4

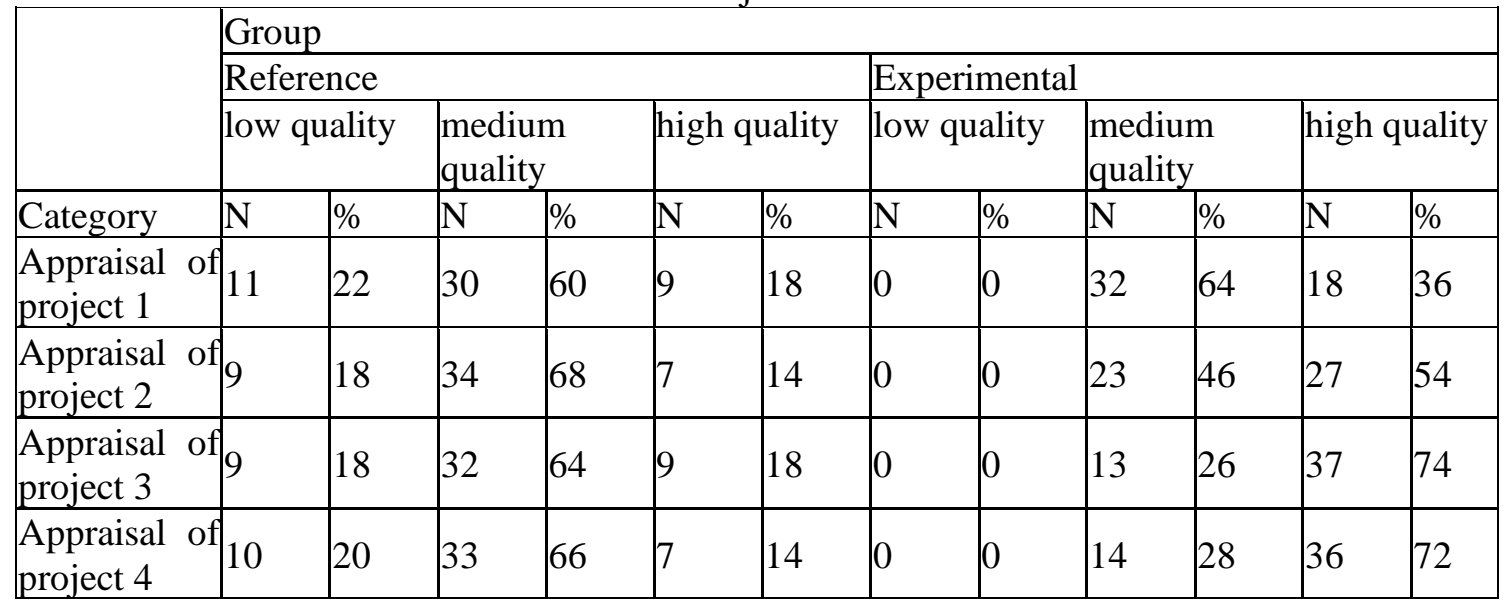

Table (4): Average and standard deviations of work quality on Project 1, Project 2, Project 3 , and Project 4

\begin{tabular}{|c|c|c|c|c|c|}
\hline Category & Group & $\mathrm{N}$ & M & SD & t-test \\
\hline Appraisal & \begin{tabular}{l|l} 
of 1. Reference \\
\end{tabular} & 50 & 6.96 & 1.400 & \multirow{2}{*}{-4.454} \\
\hline project 1 & 2. Experimental & 50 & 8.36 & .754 & \\
\hline Appraisal & of 1. Reference & 50 & 7.04 & 1.345 & \multirow{2}{*}{-4.846} \\
\hline project 2 & 2. Experimental & 50 & 8.52 & .725 & \\
\hline Appraisal & of 1. Reference & 50 & 6.88 & 1.393 & \multirow{2}{*}{-6.729} \\
\hline project 3 & 2. Experimental & 50 & 9.00 & .637 & \\
\hline Appraisal & of 1 . Reference & 50 & 7.00 & 1.443 & \multirow{2}{*}{-5.942} \\
\hline project 4 & 2. Experimental & 50 & 9.02 & .788 & \\
\hline
\end{tabular}

Satisfaction of students with BYOD course is summarized in Tables 5-6.

Table (5): Frequency and percentage for satisfaction level of student for course

\begin{tabular}{|c|c|c|c|c|c|c|c|c|c|c|c|c|}
\hline & \multicolumn{12}{|c|}{ Group } \\
\hline & \multicolumn{6}{|c|}{ Reference } & \multicolumn{6}{|c|}{ Experimental } \\
\hline & \multicolumn{2}{|c|}{$\begin{array}{l}\text { low } \\
\text { satisfaction }\end{array}$} & \multicolumn{2}{|c|}{$\begin{array}{l}\text { medium } \\
\text { satisfaction }\end{array}$} & \multicolumn{2}{|c|}{$\begin{array}{l}\text { high } \\
\text { satisfaction }\end{array}$} & \multicolumn{2}{|c|}{$\begin{array}{l}\text { low } \\
\text { satisfaction }\end{array}$} & \multicolumn{2}{|c|}{$\begin{array}{l}\text { medium } \\
\text { satisfaction }\end{array}$} & \multicolumn{2}{|c|}{$\begin{array}{l}\text { high } \\
\text { satisfaction }\end{array}$} \\
\hline & $\mathrm{N}$ & $\%$ & $\mathrm{~N}$ & $\%$ & $\mathrm{~N}$ & $\%$ & $\mathrm{~N}$ & $\%$ & $\mathrm{~N}$ & $\%$ & $\mathrm{~N}$ & $\%$ \\
\hline $\begin{array}{|lr|}\text { Level } & \text { of } \\
\text { satisfaction } & \text { with } \\
\text { the } & \text { learning } \\
\text { course } & \end{array}$ & & 42 & 20 & 40 & 9 & 18 & 0 & 0 & 11 & 22 & 39 & 78 \\
\hline
\end{tabular}

Table (6): Average and standard deviations of attendance and participation of students

\begin{tabular}{|c|c|c|c|c|c|}
\hline & Group & $\mathrm{N}$ & M & SD & t-test \\
\hline \multirow{2}{*}{$\begin{array}{l}\text { Attendance } \\
\text { participation }\end{array}$} & and 1 . Reference & 50 & 6.80 & 1.865 & \multirow{2}{*}{-3.843} \\
\hline & 2. Experimental & 50 & 9.01 & .810 & \\
\hline
\end{tabular}

\section{Discussion}


The first research task concerned the influence of BYOD on academic performance of undergraduate students measured by their scores for two e-tests and final course marks. The results demonstrated that the experimental group was by far superior to the reference group regarding Tests 1 and 2 and final course marks. For independent samples the t-test for Test 1 demonstrated statistically significant differences between the two groups, $\mathrm{t}=-3.843(\mathrm{p}<0.001)$. Experimental group showed better results $(\mathrm{M}=22.44, \mathrm{SD}=1.816)$ in comparison with the reference group $(\mathrm{M}=18.84, \mathrm{SD}=4.116)$. The t-test for two samples for Test 2 also demonstrated statistically significant differences between two groups, $\mathrm{t}=-4.121(\mathrm{p}<0.001)$; the experimental group also achieved higher scores $(\mathrm{M}=22.84, \mathrm{SD}=1.784)$ in comparison with the reference group $(M=18.56, S D=4.673)$. The obtained results also demonstrated strong significant influence of BYOD on final marks of the students, $t=-4.810(\mathrm{p}<0.001)$; the BYOD students obtained higher marks $(\mathrm{M}=88.96, \mathrm{SD}=6.769)$ in comparison with the reference group $(\mathrm{M}=71.84, \mathrm{SD}=15.668)$. Therefore, significant positive correlation between BYODbased learning and academic performance of students was obvious.

The second research task concerned the influence of BYOD on quality of work on four object-oriented course projects. The obtained results clearly evidenced that the experimental group was superior to the reference group in terms of the scores for Projects 1,2,3 and 4, as well as provided decisive evidences of the fact that the types of access to learning and opportunities of BYOD learning environment resulted in statistically significant positive changes in work quality of students. The t-test of independent samples for Project 1 showed statistically significant difference between the two groups, $t=-4.454(p<0.001)$. Most works of the experimental group on Project 1 were evaluated as of high or medium quality getting higher scores $(\mathrm{M}=8.336, \mathrm{SD}=0.754)$ in comparison with the reference group, the works of which were evaluated as of medium or low quality $(\mathrm{M}=6.96, \mathrm{SD}=1.400)$. Similarly, the t-test for independent samples for Project 2 demonstrated statistically significant difference between the two groups, $\mathrm{t}=-4.846(\mathrm{p}<0.001)$. Most works of the experimental group on this project were referred to the category of high or medium quality, and the students received higher scores $(\mathrm{M}=$ $8.52, \mathrm{SD}=0.725$ ) in comparison with the students of the reference group, whose works were referred to the category of medium or low quality $(\mathrm{M}=7.04, \mathrm{SD}=1.345)$. The results also demonstrated statistically significant positive influence of BYOD on quality of work on Project $3, t=-6.729(p<0.001)$. Most works of the BYOD group on this project were evaluated as of high or medium quality, and the students received higher scores $(M=9.00, S D=0.637)$ in comparison with the reference group, whose works on this project were evaluated mainly as of medium or low quality $(\mathrm{M}=6.88$. $\mathrm{SD}=1.393)$. Similarly, the $\mathrm{t}$-test of independent sample for Project 4 demonstrated significant difference between the two groups, $t=-5.942(p<0.001)$. Most works of the experimental group on this project were referred to the category of high or medium quality, and the students received higher scores $(\mathrm{M}=9.02, \mathrm{SD}=0.788)$ in comparison with the reference group, whose works were referred to the category of medium or low quality $(\mathrm{M}=7.00, \mathrm{SD}=1.443)$. Thus, the significant positive interrelation between BYOD and quality of works was demonstrated.

The third research task concerned the influence of BYOD on students' satisfaction with the course, including their perception, attitude, motivation, involvement and interest to the course, as well as attendance records. The obtained results demonstrated that satisfaction of the experimental group was significantly higher than that of the reference group (78\% versus $18 \%$ ). In particular, the t-test for independent samples regarding attendance and participation showed statistically significant difference between the two groups, $t=-5.080(\mathrm{p}<0.001)$. The students of the BYOD group received higher scores $(\mathrm{M}=9.01, \mathrm{SD}=0.810)$ in comparison with those of the reference group $(\mathrm{M}=6.80, \mathrm{SD}=1.865)$. Therefore, the BYOD conditions of teaching and learning demonstrated significant positive influence on perception, attitude, motivation and involvement of students into learning course and on their satisfaction.

In total, the results of this research demonstrate that BYOD can serve as a lever for teaching and learning. The BYOD model exerted significant positive influence on academic 
performance of students. In particular, the consequences were as follows: (a) improved results of tests; (b) improved quality of students' projects (with respective marks for the projects); (c) improved skills of cooperation and communication of the students; (d) enhanced interest, motivation, and involvement of students into their own learning and personal growth, as well as their satisfaction with the course; and finally (e) higher final marks of the students.

Therefore, these results confirm the research hypotheses. Moreover, these results agree with the results of other works (Livas, Katsanakis, Vayia, 2019; Cheng, Guan, Chau, 2016; Hung, 2017; Hao, 2016; Zahadat et al., 2015; Song, Wen, 2018; Kong, Song, 2015; Parsons, Adhikari, 2016; Hawkes, Hategekimana, 2009) performed in recent decade and measuring academic performance of students in all disciplines and education levels.

\section{Conclusion}

The use of ICT is very promising for improvement of teaching and learning. The results of development and teaching of students, such as academic performance, behavior, attitude, involvement, motivation, attention, self-assessment, learning habits, social skills, skills in ICT and efficiency, influence positively the use of ICT-mediated technologies/software in educational entities, including BYOD for all levels of education and various disciplines.

The performed study has provided empiric evidences of efficiency and significance of BYOD for improvement of pedagogical practice and improvement of students' academic performance.

Therefore, the experimental results have confirmed the hypotheses about positive influence of BYOD on education and academic performance of students, measured by their academic test scores, their final marks, and quality of their classroom work, as well as about the fact that implementation of BYOD will stimulate and motivate students, thus influencing their level of involvement into creation of independent learning.

However, the obtained results cannot completely assist administrators and researchers of educational technologies to find suitable solutions to the educational problems. These results cannot be mandatory confirmed and generalized; thus, further investigations are required (both qualitative and quantitative, including longitudinal study) with wider range of students, disciplines, independent/factor variables (for instance, gender, specialty, average scores, previous knowledge in the field of ICT and previous results/achievements). This could provide higher accuracy, reliability and confidence in the obtained results. Therefore, it is possible to derive a scale of progress regarding academic performance of students before and after implementation of BYOD.

The recommendations for future investigations are as follows:

1. It would be better to perform quantitative and qualitative investigations with wider scope of students, subjects (ICT and non-ICT classes), environments and variables.

2. Qualitative analysis should be used, and in quantitative investigations other demographic independent variables should be considered (for instance, gender, main properties, average scores, previous knowledge in the field of ICT and previous results/achievements).

3. BYOD incentives require for creative pedagogical frames, the future studies should attentively consider this important issue.

4. BYOD is characterized by high potential advantages, as demonstrated in this work, and moderate investments. Nevertheless, this technology is undoubtfully accompanied by significant operational expenses in time. Deployment of BYOD program in any company 
requires for attention to numerous factors, including the issues of safety, which should be considered in more details in the future. However, as an alternative to conventional technological approach, future research should be concentrated on the following aspects of BYOD: technology, policy, management system, integration of users and factors of ambient environment.

Therefore, availability of ICT-mediated initiatives, such as BYOD, can assist in shifting of paradigm from a teacher as a central facilitator, who integrates ICT in class, to the situation when students become more responsible for their own education and development. Nevertheless, teachers should be well informed about when and how to apply efficiently the tools and services of ICT as meaningful training aids in the context of education and for all kinds of students, as well as about ways of distribution of this knowledge among their students.

\section{Referencias}

Afreen, R. (2014). Bring your own device (BYOD) in higher education: Opportunities and challenges. International Journal of Emerging Trends \& Technology in Computer Science, 3(1): 233-236.

Akhyadov, E.S.M., Goncharov, V.V., Makushkin, S.A. (2020). Video marketing in education: attracting applicants using the youtube service. Revista Inclusiones, 7 Especial: $387-396$.

Alden, J. (2013). Accommodating mobile learning in college programs. Journal of Asynchronous Learning Networks, 17(1): 109-122.

Alekseev, E.V., Pinkovskaya, G.V., Ustinova, Y.V., Ermolaeva, E.O., Romanishina, T.S. (2020). Regulation and financing of environmental programs: development of public-private partnerships in the digital economy. Revista Inclusiones, 7 Especial: 372-385.

Ally, M. (2013). Mobile learning: from research to practice to Impact Education. Learning and Teaching in Higher Education: Gulf Perspectives, 10(2).

Ash, K. (2009). A faster and more reliable wireless standard is putting wireless-network expansion high on the priority list as schools' digital needs grow. Digital Directions, 3(1): 32-34.

Bernard, R.M., Borokhovski, E., Schmid, R.F., Tamim, R.M., Abrami, P.C. (2014). A metaanalysis of blended learning and technology use in higher education: From the general to the applied. Journal of Computing in Higher Education, 26(1): 87-122.

Burns, S.M., Lohenry, K. (2010). Cellular phone use in class: Implications for teaching and learning a pilot study. College Student Journal, 44(3): 805-810.

Cheng, G., Guan, Y., Chau, J. (2016). An empirical study towards understanding user acceptance of bring your own device (BYOD) in higher education. Australasian Journal of Educational Technology, 32: 1-17.

Cochrane, T., Antonczak, L., Keegan, H., Narayan, V. (2014). Riding the wave of BYOD: Developing a framework for creative pedagogies. Research in Learning Technology, 22(1): 1-14.

Dunleavy, M., Heinecke, W.F. (2008). The impact of 1:1 laptop use on middle school math and science standardized test scores. Computers in the Schools, 24(3): 7-22.

El-Hussein, M.O.M., Cronje, J.C. (2010). Defining mobile learning in the higher education landscape. Educational Technology \& Society, 13(3): 12-21.

Falloon, G. (2015). What's the difference? Learning collaboratively using iPads in conventional classrooms. Computers \& Education, 84: 62-77.

Foti, M.K., Mendez, J. (2014). Mobile Learning: How Students Use Mobile Devices to Support Learning. Journal of Literacy and Technology, 15(3): 58-78.

Franklin, T., Peng, L. (2008). Mobile math: Math educators and students engage in mobile learning. Journal of Computing in Higher Education, 20(2): 69-80.

Gil-Rodríguez, E.P., Rebaque-Rivas, P. (2010). Mobile Learning and Commuting: Contextual Interview and Design of Mobile Scenarios. Springer, 63(89): 266-277. 
Goncharov, V.V., Stepanova, D.I., Kovalev, D.V., Kovaleva, T.A., Batyrshina, A.R. (2020). Blended learning perspectives for students (university experience under constraints due to COVID-19 pandemic). Revista Inclusiones, 7 Especial: 288-300.

Graham, C. (2016). Mckercher Gillies To BYOD or not to BYOD: factors affecting academic acceptance of student mobile devices in the classroom. Research in Learning Technology, 24.

Hao, Y. (2016). Exploring undergraduates' perspectives and flipped learning readiness in their flipped classrooms. Computers in Human Behavior, 59: 82-92.

Hawkes, M., Hategekimana, C. (2009). Impacts of mobile computing on student learning in the university: A comparison of course assessment data. Journal of Educational Technology Systems, 38(1): 63-74.

Henderson, K., Gibson, C., Gibb, F. (2013). The impact of tablet computers on students with disabilities in a higher education setting. Technology and Disability, 25(2): 61-76.

Hloden, O. (2010). Mobile learning anytime, anywhere. Bioscience, 60(9): 682.

Hooft, M., Vahey, P. (2007). Handheld computers in education: An industry perspective. Educational Technology, May/June: 40-43.

Hrastinski, S. (2008). Asynchronous and synchronous e-Learning. Educause Quarterly, 31(4): 51-55.

Hung, H.T. (2017). Clickers in the flipped classroom: Bring your own device (BYOD) to promote student learning. Interactive Learning Environments, 25: 983-995.

Hwang, G.J., Tsai, C.C. (2011). Research trends in mobile and ubiquitous learning: a review of publications in selected journals from 2001 to 2010. British Journal of Educational Technology, 42(4): 65-70.

Johnson, D. (2012). On board with BYOD. Educational Leadership, 70(2): 84-85.

Khedr, A.E., Idrees, A.M. (2017). Enhanced e-Learning System for e-Courses Based on Cloud Computing. Journal of Computers, 12(1): 10-19.

Kinash, S., Brand, J., Mathew, T. (2012). Challenging mobile learning discourse through research: Student perceptions of Blackboard Mobile Learn and iPads. Australasian Journal of Educational Technology, 28(4): 639-655.

King-Sears, M. (2009). Universal design for learning: Technology and pedagogy. Learning Disability Quarterly, 34(4): 199-201.

Kobus, M.B.W., Rietveld, P., van Ommeren, J.N. (2013). Ownership versus on-campus use of mobile IT devices by university students. Computers \& Education, 68: 29-41.

Kong, S.C., Song, Y. (2015). An experience of personalized learning hub initiative embedding BYOD for reflective engagement in higher education// Computers \& Education, 88: 227-240.

LaMaster, J., Stager, G. (2012). Point/CounterPoint. Should students use their own devices in the classroom? Learning \& Leading with Technology, 39(5): 6-7.

Lennon, R.G. (2012). Bring your own device (BYOD) with Cloud 4 education. Proceedings of the 3rd annual conference on Systems, programming, and applications: software for humanity - SPLASH'12. Indianapolis: ACM Press.

Liu, T.C. (2007). Teaching in a wireless learning environment: A case study. Educational Technology and Society, 10(1): 107-123

Livas, C., Katsanakis, I., Vayia, E. (2019). Perceived impact of BYOD initiatives on postsecondary students' learning, behaviour and wellbeing: The perspective of educators in Greece. The Journal of Education and Information Technologies, 24, 489-508.

Myers, B.A., Beigl, M. (2003). Handheld computing. Computer: 27-29.

Nuhoglu, P., Gundiz, A.Y., Akkoyunlu, B. (2019). Implementing Bring Your Own Device (BYOD) Model in Flipped Learning: Advantages and Challenges. Technology, Knowledge and Learning.

O'Bannon, B.W., Thomas, K.M. (2015). Mobile phones in the classroom: Preservice teachers answer the call. Computers \& Education, 85: 110-122.

Parsons, D., Adhikar, J. (2016). Bring Your Own Device to Secondary School: The Perceptions of Teachers, Students and Parents. The Electronic Journal of e-Learning, 14: $66-80$ 
Parsons, D., Adhikari, J. (2016). Bring Your Own Device to secondary school: The perceptions of teachers, students and parents. The Electronic Journal of e-Learning, 14(1): 66-80.

Ramazanova, D., Togaibayeva, A., Turebayeva, K., Yessengulova, M., Kartbayeva, Z., Imzharova, Z. (2020). Religious Approach to The Problem of Education in V.V. Zenkovsky's Orthodox Pedagogy. European Journal of Science and Theology, 16(6): 27-36.

Safar, A.H. (2017). Educators' perceptions toward the Law on Combating Information Technology Crimes in the State of Kuwait. Educational and Social Studies, 23(1): 43-122.

Selwyn, N. (2007). The use of computer technology in university teaching and learning: A critical perspective. Journal of Computer Assisted Learning, 23(2): 83-94.

Sherblom, J.C. (2010). The computer-mediated communication (CMC) classroom: A challenge of medium, presence, interaction, identity, and relationship. Communication Education, 59: 497-523.

Song, Y. (2014). "Bring Your Own Device (BYOD)" for seamless science inquiry in a primary school. Computers \& Education, 74: 50-60.

Song, Y., Kong, S.C. (2017). Affordances and constraints of BYOD (Bring Your Own Device) for learning and teaching in higher education: Teachers' perspectives. The Internet and Higher Education, 32: 39-46.

Song, Y.J., Wen, Y. (2018). Integrating Various Apps on BYOD (Bring Your Own Device) into Seamless Inquiry-Based Learning to Enhance Primary Students' Science Learning. Journal of Science Education and Technology, 27: 165-176.

Stonebraker, I.R., Robertshaw, M.B., Kirkwood, H.P., Dugan, M. (2014). Bring Your Own Device in the Information Literacy Classroom. Indiana Libraries, 33: 64-67.

Tereshchenko, E.A., Kovalev, V.V., Trofimov, M.S., Zasseev, D.A. (2020). Legal consciousness as a factor promoting the achievement of educational objectives and the realization of the right to education by individuals and collectives. Revista Tempos E Espaços Em Educação, 13(32): 1-21. https://doi.org/10.20952/revtee.v13i32.14690

Tomasz, L., Bajdor, P. (2015). The use of Cloud Computing by Students from Technical University - the Current State and Perspectives. Procedia Computer Science, 65: 1075-1084.

Varenina, L.P., Goncharov, V.V., Tonoyan, Kh.A., Bazhin, G.M., Ismailova, Kh.E. (2020). Organization of teacher-student pedagogical interaction in blended learning through mobile messengers. Revista Inclusiones, 7 Especial: 357- 368.

Vázquez-Cano, E. (2014). Mobile distance learning with smartphones and apps in higher education. Educational Sciences: Theory and Practice, 14(4): 1505-1520.

Welsh, K.E., Mauchline, A.L., France, D., Powell, V., Whalley, W.B., Park, J. (2018). Would Bring Your Own Device (BYOD) be welcomed by undergraduate students to support their learning during fieldwork? Journal of Geography in Higher Education, 42: 356-371.

Woods, R., Baker, J.D., Hopper, D. (2004). Hybrid structures: Faculty use and perception of web-based courseware as a supplement to face-to-face instruction. Internet and Higher Education, 7: 281-297.

Zahadat, N., Blessner, P., Blackburn, T., Olson, B.A. (2015). BYOD security engineering: A framework and its Academic analysis. Computers \& Security, 55: 81-99. 